\title{
Preparing for presymptomatic DNA testing for early onset Alzheimer's disease/cerebral haemorrhage and hereditary Pick disease
}

Department of Clinical Genetics, University Hospital Dijkzigt and Erasmus University, PO Box 1738, $3000 \mathrm{DR}$ Rotterdam, The Netherlands

A Tibben

M F Niermeijer

Department of Neurology, University Hospital Dijkzigt and Erasmus University, Rotterdam, The Netherlands

$M$ Stevens

$\mathrm{J} C$ van Swieten

Department of Medical Psychology and Psychotherapy, University Hospital

Dijkzigt and Erasmus

University,

Rotterdam, The

Netherlands

A Tibben

Department of Philosophy and Medical Ethics, University Hospital

Dijkzigt and Erasmus

University,

Rotterdam, The

Netherlands

G M W R de Wert

Department of Epidemiology and Biostatistics

University Hospital

Dijkzigt and Erasmus

University,

Rotterdam, The

Netherlands

$C M$ van Duijn

Institute of Bioethics, Maastricht, The

Netherlands

G M W R de Wert

Correspondence to: Dr Tibben.

Received 13 March 1996 Revised version accepted for publication 9 August 1996 A Tibben, $M$ Stevens, G M W R de Wert, $M F$ Niermeijer, C $M$ van Duijn,
J C van Swieten

\begin{abstract}
The acceptability of presymptomatic testing in 21 people at $50 \%$ risk for the APP-692 mutation causing presenile Alzheimer's disease or cerebral haemorrhage resulting from cerebral amyloid angiopathy (FAD-CH), and in 43 people at $50 \%$ risk for hereditary Pick disease (HPD) was assessed. Neither group differed in demographic variables. Thirty-nine people $(64 \%)$ in the whole group would request presymptomatic testing if it were clinically available, although two-thirds did not yet feel ready to take it. The most important reasons in the HPD and FADCH group for taking the test were: to further basic research $(42 \%$ and $47 \%$, respectively), informing children $(47 \%$ and $50 \%$, respectively), future planning $(29 \%$ and $47 \%$, respectively), and relieving uncertainty $(46 \%$ and $27 \%$, respectively). The most commonly cited effect of an unfavourable test result concerned increasing problems for spouses $(75 \%$ and $76 \%$, respectively) and children $(61 \%$ and $57 \%$, respectively). Most respondents denied that an unfavourable result would have adverse effects on personal mood or relationship. One-third of all respondents favoured prenatal testing where one of the parents had an increased risk for HPD or FAD-CH. Participants would encourage their offspring to have the test before starting a relationship (35\%) and before family planning $(44 \%)$. Thirty-seven percent of the respondents would encourage their children to opt for prenatal diagnosis. People at risk for HPD were significantly more preoccupied with the occurrence of potential symptoms in themselves, compared with those at risk for FAD-CH, reflecting the devastating impact that disinhibition in the affected patient has on the family. Our findings underline the need for adequate counselling and the availability of professional and community resources to deal with the impact of test results in subjects and their relatives. ( $($ Med Genet 1997;34:63-72)
\end{abstract}

Keywords: presymptomatic testing; Alzheimer's disease; Pick disease.

An increasing number of neurodegenerative diseases have been defined at the molecular level in recent years, making it possible to determine the genotype precisely before the onset of symptoms. Presymptomatic testing programmes are available for Huntington's disease (HD), hereditary cerebral haemorrhage with amyloid-Dutch type, inherited cerebral ataxia, myotonic dystrophy, and Alzheimer's disease. ${ }^{1-6}$ For other autosomal dominant disorders, the genetic cause will be detected in the near, foreseeable future. Significant progress has been made in unravelling the dynamics of genes and their products. ${ }^{7}$ However, effective pharmacological or gene therapy for late onset neurodegenerative disorders is not expected to be available in the immediate future.

In a collaborative programme on neurogenetics in Rotterdam, two studies on early onset dementia are currently being carried out. The first study concerns a family with presenile Alzheimer's dementia and cerebral haemorrhage (FAD-CH). FAD-CH is caused by a mutation in codon 692 of the gene for $\beta$ amyloid precursor protein ( $\beta$ APP) on chromosome $21 .{ }^{8}$ Extracellular amyloid plaques, intraneuronal neurofibrillar tangles, and amyloid angiopathy were found in the brains of two FAD-CH patients. Mutations in the $\beta A P P$ gene account for less than $3 \%$ of disease onset before 65 years of age. ${ }^{8}$

In a second study, early onset Pick disease was found in three Dutch families with an autosomal dominant transmission pattern over five to seven generations. The typical clinical features in the patients with hereditary Pick disease (HPD) were disinhibition, stereotyped behaviour, roaming, and hyperorality. Frontal and temporal atrophy on CT scan supported the clinical diagnosis in eight, two, and five living patients in the three families, respectively. The diagnosis of HPD was confirmed in each family by pathological examination of the brain in one, 14, and 15 patients, respectively. Macroscopic examinations showed selective atrophy of the frontal cortex, non-specific changes (neuronal loss, spongiosis, gliosis), and ballooned cells. Evidence was found in these three families for linkage of HPD to chromosome $17 .^{27}$

$\mathrm{HPD}$ and $\mathrm{FAD}-\mathrm{CH}$ are primary degenerative diseases of the brain, with onset usually in the fourth to sixth decades of life. ${ }^{9-12}$ Both conditions have an average age of onset between 40 and 60 years of age. The course in both disorders is variable, with the development of profound dementia ranging from two to 10 years after diagnosis. No specific treatment is 
available, but the use of palliative treatments is now being explored.

Misdiagnosis of HPD or FAD-CH, such as depression (FAD-CH) or manic states (HPD), may occur in the early stages of the disease and has often led to unsuccessful psychotherapy of couples. The diagnosis of FAD-CH and HPD is psychologically devastating to the partner and his/her offspring, who have seen the patient's parent, sib, or another close relative become progressively disabled. People sometimes incorrectly believe themselves to be at risk because of symptom searching or preoccupation with early signs. Often, "soft" signs, which are not specific for FAD-CH or HPD, are perceived as a precursor of the disease.

Genetic mutational or linkage analysis may confirm the diagnosis in patients with HPD or FAD-CH and could provide presymptomatic testing for at risk subjects. Presymptomatic testing for Huntington's disease is considered as the paradigm for prediction programmes for other late onset neurodegenerative diseases and cancers ${ }^{13}$ and should provide the experience necessary to improve pretest and post-test counselling. Before the introduction of the predictive test, attitudinal studies among those at risk for Huntington's disease have shown that the commonly cited reasons for taking the predictive test were the unbearable uncertainty, anticipating the future, and planning a family, but that an unfavourable result might also lead to depressive feelings and suicidal behaviour. ${ }^{14-16}$ These surveys indicated that the majority would make use of a predictive test if it were available. With careful consideration of the ethical, clinical, and legal implications of presymptomatic testing for an incurable late onset disease, ${ }^{1317-19}$ guidelines were carefully developed and testing was carried out cautiously in research settings. ${ }^{20}$ To date, requests for the test have been far below the expected rate, although in The Netherlands 150 people apply for it yearly, and about $15 \%$ of the estimated cohort at $50 \%$ risk has received test results. ${ }^{2122}$ Only a small amount of experience has been reported on testing for presenile dementia. In Sweden, one out of three people tested at $50 \%$ risk for the APP $670 / 671$ mutation was identified as a mutation carrier. After a one year period with depressive feelings and suicidal thoughts, this subject could eventually handle his situation. Intensive attention and care at the genetics clinic was needed. The non-carriers had expressed their relief. ${ }^{23} \mathrm{Al}$ though the potential benefits of predictive testing may include relieving uncertainty and planning the future, the acceptability of, and need for, presymptomatic testing for early onset dementia has not yet been established. ${ }^{2425}$

This study addresses the impact of approaching families with a hereditary presenile dementia for genetic research with the aim of establishing a predictive testing programme, as was done for Huntington's disease. We studied the ability to cope with being at risk for HPD or FAD-CH, the influence of the disease upon a variety of areas of life, and the attitude towards presymptomatic testing. Guided by our clinical experience with these neurodegenerative dis- orders, we expected similar attitudes as were found in people at risk for Huntington's disease in the Dutch presymptomatic testing programme. ${ }^{26}$ The results could be helpful for the medical-ethical evaluation of this and other genetic research programmes, to establish a suitable, disease specific testing protocol, and to develop support strategies when testing does become available.

\section{Subjects and methods}

Clinical, genetic-epidemiological, and pathological research was conducted on FAD-CH and HPD in a collaborative programme in Rotterdam, The Netherlands. DNA linkage and mutation studies were done in one family with familial early onset FAD- $\mathrm{CH}^{8}$ and three families with HPD. ${ }^{27}{ }^{28}$ Participants were at $50 \%$ risk for HPD $(n=43)$ or FAD-CH $(n=$ 21) and cooperated after fully informed consent. Participants had a general medical examination, neurological examination, neuropsychological testing, brain imaging (MRI scan), blood sampling, and were asked to participate in a clinical psychological assessment and an attitudinal survey. The Medical Ethics Committee of the University Hospital Dijkzigt, Rotterdam, approved the protocols. Participants were informed about the disease (MS, $\mathrm{CMvD}, \mathrm{JCvS}$ ), and received information about the genetic pattern of familial FAD-CH or HPD. They were referred, when needed, to the Clinical Genetics Department for further genetic counselling (MFN) or psychological support (AT).

Forty-three out of 50 people at risk for HPD $(86 \%)$ and 21 out of 26 people at risk for FAD-CH (81\%) gave consent for the clinical psychological study which consisted of an in depth interview and administering psychological questionnaires that were completed at home. Questionnaires were returned within a week after the interview. Demographic data (gender, age, marital status, employment status, number of children, number of sibs, and level of education) were collected. An Attitude Questionnaire (AQ) was administered that consisted of questions on the following areas: experience of the disorder, the age at which the person learned about the heredity of HPD or FAD-CH, the subject's attitudes towards taking the presymptomatic test, the expected outcome of the test, and attitudes toward prenatal testing and terminating a pregnancy in different circumstances. Most questions had the response categories yes/agree, don't know, no/not agree. Questions on experience of the disease, impact on personal life, and reasons for and against predictive testing were open ended, for which response categories were compiled to suit the common themes emerging from the answers. The estimated risk of inheriting the gene or developing the disease was assessed using a visual analogue scale. People who considered taking a future predictive test when it became clinically available answered questions about the anticipated impact of either test results. The AQ was adapted from the Dutch Huntington Presymptomatic Programme. ${ }^{26}$ 
Table 1 Characteristics of people at risk for hereditary Pick disease (HPD) and familial Alzheimer's disease/cerebral haemorrhage (FAD-CH)

\begin{tabular}{|c|c|c|}
\hline & $H P D(n=43)$ & $F A D-C H(n=21)$ \\
\hline \multicolumn{3}{|l|}{ Mean age } \\
\hline Years (range) & $38.7(21-61)$ & $38.1(22-60)$ \\
\hline & 9.7 & 10.4 \\
\hline $\begin{array}{l}\text { Time lag* } \\
\text { Years (range) }\end{array}$ & & \\
\hline Years (range) & $\begin{array}{l}3.4(0-37) \\
8.9\end{array}$ & $\begin{array}{l}6.6(0-40) \\
6.9\end{array}$ \\
\hline \multicolumn{3}{|l|}{ No of affected relatives $†$} \\
\hline $\begin{array}{l}\text { Range } \\
\text { Male/female ratio }\end{array}$ & $\begin{array}{l}3.0(1-7) \\
21 / 22\end{array}$ & $\begin{array}{r}1.0 \\
12 / 9\end{array}$ \\
\hline \multirow{2}{*}{\multicolumn{3}{|c|}{ Marital status }} \\
\hline & & \\
\hline Single & $10(23)$ & $2(10)$ \\
\hline Married & $26(61)$ & $14(67)$ \\
\hline Common law & $6(14)$ & $2(10)$ \\
\hline $\begin{array}{l}\text { Widow } \\
\text { Divorced }\end{array}$ & $1(2)$ & \\
\hline \multirow{2}{*}{\multicolumn{3}{|c|}{ Children }} \\
\hline & & \\
\hline 0 children & $17(40)$ & $9(43)$ \\
\hline $\begin{array}{l}1 \text { child } \\
\geq 2 \text { children }\end{array}$ & $4(09)$ & $3(14)$ \\
\hline \multirow{2}{*}{$\begin{array}{l}\geq 2 \text { children } \\
\text { Highest level of education } \\
\text { Elementary/lower vocational school } \\
\geq \text { High school }\end{array}$} & $22(51)$ & $9(43)$ \\
\hline & $\begin{array}{l}14(33) \\
29(67)\end{array}$ & $\begin{array}{r}9(43) \\
12(57)\end{array}$ \\
\hline
\end{tabular}

* Period that had elapsed since participant learned about personal risk for FAD-CH/HPD. t First or second degree.
LEARNING ABOUT HPD OR FAD-CH AND PERSONAL RISK

The average period that had elapsed (time lag) since participants first learned about their personal risks was about six years in both groups (table 1). However, $24 \%$ of the group at risk for FAD-CH and $45 \%$ of the HPD group first heard about their personal risks during this study. Eighty percent of both groups at risk learned about their own risk after the age of 18 years, at a mean age of 25.9 years (SD 8.6) and 26.5 years (SD 11.3). In the interviews, some people reported severe reactions, such as depressive feelings, guilt towards spouse and children, sleeping disturbances, phobic reactions, and marital problems. For others, participation in the genetic study meant relief because the scientific attention had given them some hope for the future.

UPTAKE OF PRESYMPTOMATIC TESTING

Twenty-seven people at risk for HPD (68\%) and 12 at risk for FAD-CH $(57 \%)$ would take the presymptomatic test when it became clinically available, whereas five (13\%) and three (14\%) people in either group were still uncertain about it. Nineteen (49\%) out of the total group of 39 people who would take the test indicated that they would use it as soon as it became available. The others did not feel prepared to learn about precise risks at this stage. Eight people at risk for HPD (20\%) and six at risk for FAD-CH (26\%) would not take the test.

Those who would not take the presymptomatic test were also against testing minors ( $<18$ years). Half of the group that considered predictive testing held the opinion that children under 18 should be allowed to have the test. No differences were found between the HPD and the FAD-CH groups.

DEMOGRAPHIC INFORMATION

The demographic information on the participants is given in table 1 . Thirty-four subjects at $50 \%$ risk for HPD and 21 for FAD-CH participated in the study on gene localisation, and all except three from the HPD group completed the psychological questionnaires. The latter three people withdrew from the study because they felt too anxious about their risk after having undergone the entire procedure. No significant differences were found between the HPD and FAD-CH groups. The majority had a stable relationship and fewer than half had no children. Participants with children $(60 \%)$ had a mean of two children.

\section{REASONS FOR OR AGAINST PRESYMPTOMATIC} TESTING

For people who would take or consider taking a future presymptomatic test, the major reasons for uptake are presented in table 2. Generally, those at risk for either FAD-CH or HPD cited similar reasons. Almost half of the participants declared their reasons as: helping research, informing their children, general planning for the future, and relieving uncertainty. Planning a family was only a minor reason for uptake.

Table 2 Reasons* for taking the presymptomatic DNA test for hereditary Pick disease (HPD) or familial Alzheimer's disease/cerebral haemorrhage (FAD-CH)

\begin{tabular}{llll}
\hline & $H P D+(n=32)$ & FAD-CH+ $(n=15)$ & \\
\cline { 2 - 4 } & No (\%) & No (\%) & $95 \%$ CI for differences \\
\hline (1) For the sake of children/clarify risk to children & $16(50)$ & $7(47)$ & $(-27 ; 34)$ \\
(2) To help research/to stop the disease & $13(42)$ & $7(47)$ & $(-37 ; 24)$ \\
(3) General planning for the future & $9(29)$ & $7(47)$ & $(-48 ; 11)$ \\
(4) To relieve uncertainty & $15(46)$ & $4(27)$ & $(-08 ; 49)$ \\
(5) To plan a family & $3(8)$ & $3(20)$ & $(-33 ; 12)$ \\
(6) To prepare for the future (anticipating the disease) & $4(13)$ & $3(20)$ & $(-31 ; 16)$ \\
(7) Insurance & - & $2(13)$ & $(-31 ; 04)$ \\
\hline
\end{tabular}

* This was an open ended question; more than one reason could be given.

† Answered by those who would consider taking the presymptomatic test. 
Table 3 Impact of hereditary Pick disease (HPD) or familial Alzheimer's disease/cerebral haemorrhage (FAD-CH) on life of people at $50 \%$ risk

\begin{tabular}{llcl}
\hline & $H P D(n=40)$ & FAD-CH $(n=21)$ & \\
\cline { 2 - 4 } & $N o(\%)$ & No (\%) & $95 \%$ CI for differences \\
\hline (1) Preoccupation with symptoms & $24(60)$ & $3(14)$ & $(24 ; 67)$ \\
(2) Restriction in planning the future & $21(53)$ & $7(33)$ & $(-06 ; 45)$ \\
(3) Anxiety, depression, uncertainty & $24(60)$ & $6(29)$ & $(-136)$ \\
(4) Disturbance of family life & $5(13)$ & $2(10)$ & $(-36 ;-02)$ \\
(5) Positive influence & $8(20)$ & $11(52)$ & $(-57 ;-08)$ \\
(6) No influence & & & \\
\hline
\end{tabular}

Table 4 Most significant symptoms* of hereditary Pick disease (HPD or familial Alzheimer's disease/cerebral haemorrhage (FAD-CH) as perceived and experienced by people at risk

\begin{tabular}{llll}
\hline & $H P D(n=40)$ & FAD-CH $(n=21)$ & 95\% CI for differences \\
\cline { 2 - 4 } & $N o(\%)$ & No (\%) & $(-23 ; 25)$ \\
\hline (1) Change of personality & $12(30)$ & $6(29)$ & $(48 ; 82)$ \\
Disinhibition/restlessness & $28(70)$ & $1(5)$ & $(-11 ; 33)$ \\
Loss of insight and judgement & $12(30)$ & $4(19)$ & $(-22 ; 03)$ \\
Emotional lability/euphoria & $9(23)$ & $1(5)$ & $(02 ; 34)$ \\
Lack of spontaneity/emotional unconcern & $4(10)$ & $3(14)$ & $(-22 ; 13)$ \\
Depressive episodes & $9(23)$ & $1(5)$ & $(-15 ; 16)$ \\
Aggression & $4(10)$ & $2(10)$ & $(-19 ; 32)$ \\
(2) Stereotyped behaviour & $17(40)$ & $7(33)$ & $(-40 ; 03)$ \\
(3) Cognitive deterioration & $4(10)$ & $6(29)$ & $(-09 ; 15)$ \\
Dysmnesia & $3(7)$ & $1(5)$ & $(02 ; 39)$ \\
Disorientation & $12(30)$ & $2(10)$ & \\
Dysphasia & & & \\
\hline
\end{tabular}

* In first or second degree affected relatives.

Two people would take the test for reasons of insurance. Considerations against presymptomatic testing were expressed by 28 people out of the group that considered predictive testing (60\%). Fear of adverse effects such as anxiety and depression after an unfavourable result was mentioned by 24 of them $(51 \%)$. Seven $(15 \%)$ emphasised that an unfavourable result would overshadow their life entirely. One person feared that an unfavourable test result might lead to being refused insurance.

Fourteen subjects who would not take the test (eight at risk for HPD (20\%) and six at risk for FAD-CH $(26 \%)$ ) cited as the main reasons against testing the fear of unfavourable test results and the inability to cope with such an outcome, preoccupation with signs of the onset of the disease, and expected distortion of the current course of life. One person feared possible misuse by insurance companies. In this group only few reasons for testing were given: the responsibility to inform children $(\mathrm{n}=$ 2), family planning $(n=2)$, and to help research $(n=2)$. No differences were found between the HPD group and the FAD-CH group.

IMPACT OF HPD/FAD-CH ON PERSONAL LIFE The impact of the disease on personal life is presented in table 3. Subjects at risk for HPD reported significantly more preoccupation with symptoms than the FAD-CH-group. More than half $(60 \%)$ of the HPD group said that the disease in their relatives had affected their mood (anxiety, depression) and had led to feelings of uncertainty. More than half (53\%) of the HPD group felt restricted in making plans for the future. Four had previously undergone sterilisation to prevent transmission of the gene to their offspring. For $\mathrm{FAD}-\mathrm{CH}$, more than half of those at risk (52\%) said that the disease had not influenced their personal life.

Comparison of the most significant symptoms of HPD/FAD-CH in affected relatives as perceived by the participants (table 4) showed that more than two-thirds $(70 \%)$ of the HPD group mentioned the disinhibition and restlessness as the most significant symptoms. In some cases, specific changes in oral/dietary behaviour and sexual disinhibition was mentioned. In the FAD-CH group at risk, the most significant symptoms were dysmnesia and personality changes.

\section{EXPECTED EFFECTS OF AN INCREASED OR} DECREASED RISK FOR HPD/FAD-CH

Previous feelings about getting the disease or not were assessed with a visual analogue scale. Twenty-seven people at risk for HPD (68\%) and 15 at risk for FAD-CH (71\%) thought that their personal risk was equal to or less than $50 \%$. Eighteen percent in the HPD group and $10 \%$ in the FAD-CH group estimated their risk as higher than $70 \%$. Anticipation of the effects of being identified as a gene carrier did not differ between the groups and showed a high awareness of the increased burden for the spouse (table 5). Participants vividly commented on how their affected parent was not aware of the deterioration in the later stages of the disease, but that the healthy parent became extremely burdened by the devastation caused by the disease and the difficult decisions to be made regarding the patient. Twenty-three percent of the HPD/FAD-CH group were afraid of becoming depressed. Forty-nine percent of the HPD/FAD-CH groups had confidence that they could cope with an unfavourable test outcome, whereas $12 \%$ stated that such a result would ruin their life. 
Table 5 The expected influence after receiving an increased risk of presymptomatic testing for hereditary Pick disease (HPD) or familial Alzheimer's disease/cerebral haemorrhage (FAD-CH)

\begin{tabular}{llll}
\hline An increased risk & $H P D\left(n=40^{*}\right)$ & FAD-CH $(n=21)$ & \\
\cline { 2 - 4 } & No $(\%)$ & No (\%) & $95 \%$ CI for differences \\
\hline Will increase the problems of my partner & $22(55)$ & $16(76)$ & $(-45 ; 03)$ \\
Will increase the problems of my children & $17(43)$ & $12(57)$ & $(-41 ; 12)$ \\
Will allow me to plan my own future better & $16(40)$ & $11(52)$ & $(-39 ; 14)$ \\
Will allow me to plan the future of my family better & $14(35)$ & $11(52)$ & $(-44 ; 09)$ \\
Will increase my problems & $16(40)$ & $7(33)$ & $(-19 ; 32)$ \\
Will cause me to become depressed & $9(23)$ & $3(14)$ & $(-12 ; 28)$ \\
Will adversely affect my marriage/relationship & $4(10)$ & $5(24)$ & $(-34 ; 07)$ \\
Will decrease the quality of my life & $7(18)$ & $2(10)$ & $(-09 ; 25)$
\end{tabular}

* Participants who considered uptake of presymptomatic testing.

Table 6 Attitudes of people at risk for hereditary Pick disease (HPD) and familial Alzheimer's disease/cerebral haemorrhage (FAD-CH) towards abortion in different circumstances

\begin{tabular}{|c|c|c|c|}
\hline \multirow[t]{2}{*}{ I think abortion is acceptable if } & $H P D(n=40)$ & $F A D-C H(n=21)$ & \\
\hline & No (\%) & No (\%) & $95 \%$ CI for differences \\
\hline $\begin{array}{l}\text { Health of mother is in danger because of pregnancy } \\
\text { Prenatal diagnosis shows a serious disease } \\
\text { Prenatal diagnosis shows Down syndrome } \\
\text { Prenatal diagnosis shows increased risk for HPD/FAD-CH } \\
\text { The baby is unwanted (for other than medical reasons) }\end{array}$ & $\begin{array}{l}31(78) \\
25(63) \\
18(45) \\
8(20) \\
12(30)\end{array}$ & $\begin{array}{r}20(95) \\
16(76) \\
10(48) \\
6(29) \\
6(29)\end{array}$ & $\begin{array}{l}(-34 ;-02) \\
(-37 ; 10) \\
(-29 ; 24) \\
(-32 ; 14) \\
(-23 ; 25)\end{array}$ \\
\hline
\end{tabular}

Two out of 39 subjects at risk for HPD/FAD$\mathrm{CH}$ (5\%), who would undergo presymptomatic testing, indicated in the questionnaire that they might commit suicide after an unfavourable result and nine $(23 \%)$ stated that they had not resolved this question. All but two indicated that they would seek professional help after an unfavourable test result.

The most commonly cited effect of receiving a decreased risk was a reduction in problems for spouses (70\%) and children (54\%) and improved planning for their personal future $(51 \%)$ and the family's future (49\%). Only $13 \%$ agreed that a decreased risk would improve the marriage/relationship.

EXPECTED IMPACT ON FAMILY PLANNING

Among the 26 childless people ( $41 \%$ ), six persons wished to have children and another seven were uncertain. Three people with offspring would have more children. Six of the nine who wished to have (more) children would take the presymptomatic test. In case of an unfavourable result, one of them would refrain from having children, three were uncertain about prenatal diagnosis, one would opt for pregnancy termination of a fetus with an increased risk for the disease, and one would not use prenatal testing. Two people were uncertain about taking the presymptomatic test and did not agree with prenatal diagnosis. One did not wish to learn of his or her personal status, but would opt for exclusion testing, that is, excluding whether or not a fetus has received a chromosome from the affected grandparent.

Some participants would encourage their offspring to take the test before starting a relationship (35\%), or before planning a family $(42 \%)$. If an increased risk was found in their adult child, $31 \%$ of the respondents would encourage this child to opt for prenatal diagnosis.

The majority of respondents (59\%) were against the availability of prenatal testing for
HPD or FAD-CH. When asked whether pregnancy termination was acceptable in a variety of situations (table 6), a minority of all respondents found abortion acceptable in the case of prenatal detection of an increased risk for HPD or FAD-CH $(20 \%$ and $29 \%$, respectively). Among those who found the availability of prenatal testing acceptable as a clinical service ( $n=25,41 \%), 19$ would actually use it in the event of a pregnancy in their own family, whereas nine of this subgroup would terminate the pregnancy if the fetus showed an increased risk for HPD or FAD-CH.

\section{PRESYMPTOMATIC TESTING AND ADDITIONAL} SUPPORT

Almost all participants (90\%) emphasised that extensive pretest genetic counselling is a necessity when presymptomatic testing becomes available. Counselling should include exploration of all pros and cons of testing, with the inclusion of the emotional ramifications and the impact on marital and family interactions. In addition, $82 \%$ found that psychological assessment is necessary to assess whether test candidates can cope with the test outcome. Half of the participants (49\%) held the opinion that the test should not be offered if the test candidate intends to commit suicide after an unfavourable result. Thirty-one percent stated that the test should not be offered unless the disease can be cured. Twenty-one percent felt that the test results should not be added to the medical records.

\section{Discussion}

PARTICIPATION IN PEDIGREE LINKAGE STUDIES Gene localisation and identification are obviously necessary for obtaining information about the aetiology and molecular genetic aspects of early and late onset dementia. Common interests in the insight into the hereditary nature of dementia may contribute to future 
therapeutic interventions. Half of those at risk in this study mentioned "to help research" as an important motive for participation. Yet the potential burden of participation in pedigree and linkage studies is often underestimated by researchers and medical specialists. Facing the threat of an appalling disease can cause a variety of psychological, legal, and ethical problems for people at risk. In addition, family members may learn about their own risk for the first time through participation. This problem was often the case for the groups at risk for HPD or FAD-CH. In the information sessions, many people did not fully understand all the ramifications of being at risk. Ideas about heredity were only vague and information previously obtained from professionals (neurologist, general practitioner) were often similarly unclear. Most of the participants were accordingly shocked by the information about their own risks. Is it acceptable to recruit relatives for participation in research who may not even suspect that the disease under investigation is genetic, and that they may carry genes potentially harmful to them or their offspring? For some relatives the request for participation was not ominous news because they suspected that the disease was hereditary. Other relatives may have a positive attitude towards research because genetic information may be relevant, for example, for reproductive decisions or informing their children. Refraining from conducting family studies leaves a family ignorant and might prevent members from knowing the potential threat of personal risk. The moral price of such a policy is that family members are denied the possibility of anticipating their future and making general decisions. Obtaining consent, protecting privacy and confidentiality, and safeguarding divergent and conflicting intrafamilial and intergenerational interests present moral challenges to the conduct of sound research. ${ }^{30}$ Our experience emphasises that strong collaboration of all disciplines (molecular and clinical geneticist, neurologist, psychologist, medical ethicist, general practitioner) involved is a requirement for conducting genetic studies.

Many people at risk for HPD were preoccupied with early symptoms in themselves which reflected anxiety and great concern about their future, which was different for the FAD$\mathrm{CH}$ group. The disinhibition/restlessness in the affected parent and other affected relatives was often experienced as frightening and overshadowed the lives of many of those at risk for HPD. This fear affected their self-esteem, future prospects, and their relationship with spouses and relatives. Therefore, in the programming and institutional ethical review of pedigree and linkage studies, attention must be paid to the provision of genetic and psychological counselling. Also, familiarity with genetic concepts in all medical disciplines becomes essential and medical curricula must meet such requirements.

Localisation or finding of the gene often results in the clinical application of predictive testing programmes, given the experience with Huntington's disease, polyposis coli, and breast and ovarian cancer. The predictive programme for Huntington's disease was embedded in careful genetic counselling following the international guidelines, and psychological follow up. ${ }^{203132}$ Although the medical-ethical issues and benefits of predictive testing are still under debate, the widespread application of such testing as a clinical service proceeds for untreatable genetic disorders. It is not known whether alternatives for solving the emotional and decision making problems in people at risk are offered and can be sufficiently met in health care. Predictive programmes may be too easily established as a result of finding a linkage or mutation, without proper ethical reflection or containment in a follow up research experimental condition.

Although genetic counselling often implies being the devil's advocate by discouraging people at risk from undergoing the test for diseases that have no outlook on treatment, the Huntington experience shows that applicants for the test are very determined to have test results, even in those cases where other options of dealing with the threat might be preferable. Weighing the pros and cons of testing is eventually a personal responsibility.

ACCEPTANCE OF PRESYMPTOMATIC TESTING PROGRAMMES

Both FAD-CH and HPD are rare, devastating diseases, yet the majority of participants in this study would take a presymptomatic test if it became available. As with results found in those at risk for Huntington's disease, many denied the potential untoward effects of becoming identified as a gene carrier. ${ }^{26334}$ Preparation for the future and worry about the spouse were the main reasons for taking the test, in contrast to the HD group where family planning was paramount. ${ }^{26}$ Because for the HPD/FAD-CH groups the age of onset is usually much later and the risk increases dramatically as age advances, people at risk for HPD/FAD-CH might consider testing for general planning such as retirement, medical directives, and early diagnosis and appropriate treatment. ${ }^{24}$

The purpose of counselling is to safeguard considerable deliberation. Half of the group that considered predictive testing found that testing should also be accessible for minors under 18 years, which is similar to the opinions of test candidates for Huntington's disease. ${ }^{26}$ Yet the request of parents to test their children who are minors should be rejected as this would violate the child's right "not to know". It should be safeguarded that the child can make an autonomous decision when he/she reaches the age of majority. ${ }^{35}$

Twenty-eight percent of those who considered predictive testing would either commit or consider committing suicide after becoming identified as a gene carrier, although they would seek professional support. This is similar to attitudinal studies in HD. ${ }^{16}$ Half of the participants thought that those who considered committing suicide after an unfavourable result should not be given the test. This raises the question of what is good clinical practice. Ap- 
plicants for the predictive test who are in shock or who are depressive, and who are consequently not able to make a well considered, autonomous choice, should not be given access to the test or testing should be postponed. In all cases, extensive pretest counselling is a prerequisite, in which the pros and cons of testing are explored and weighed. It should be investigated whether the suicidal intention is an indication of either a depressive state of mind or of rational considerations. In addition, the counsellor can actively raise the issue of possible adverse reactions to unfavourable test results, with the inclusion of suicide intentions. It should be noted that the experience with testing for Huntington's disease has shown that people at risk who are not able to cope with unfavourable test results exclude themselves from testing (self-exclusion). What if a competent applicant expresses his intentions to commit suicide after unfavourable results? Should access to the test be refused in such cases? Such a policy has certain objections. First, prohibition of testing of those considering suicide would lead to the concealment of suicidal intentions, as was experienced in the HD presymptomatic testing programme. Second, unconditional refusal of access to testing would be a violation of the principle of autonomy. This principle implies the professional respect for the applicant's considerations regarding the consequences of either test result. Moreover, refusal of access to the test has its moral price because this would force test candidates to remain uncertain about their genetic status. Suicide is not immoral and the intention to commit suicide in certain circumstances not unreasonable. Hence, suicide in case of an unfavourable test result is not a priori irrational. Consequently, it is, in our opinion, a priori morally tenable to allow access to a future predictive test if an applicant expresses his intention to commit suicide after unfavourable test results. In conclusion, we recommend that anxieties and expectancies regarding one's fate be openly discussed. Testing may be postponed and additional support offered when needed. It should also be noted that, as clinical experience with Huntington's disease has shown, suicide may become an option in the final stages of the disease, and not as a reaction to an increased risk test result or after onset of the first signs of the disorder.

People who are the first in a family to participate in genetic studies and presymptomatic testing programmes may assume the responsibility for informing their offspring and relatives about the new information. In the families studied, the key person was often the patient's spouse with whom the heredity of the disease was first discussed and who consented by proxy to testing the affected patient. Such proxy consent is acceptable given the potential interests of children and other relatives with regard to certainty about personal risks, or the relevance of differential diagnosis. In addition, confirmation of diagnosis using DNA testing does not conflict with the demented patient's interests. It may be objected, however, that the potential interests of children and other relatives disqualify them as proxy. Therefore, good medical and ethical practice requires close consideration and discussion whether personal interests interfere with being a proxy.

Information on genetic studies may cause emotional upheaval in relatives who are informed and resentment against the informants. Informing and supporting people with this specific mission about these family issues, which are usually unexpected, may stimulate other relatives to appreciate the value of family studies.

The intended uptake of testing among the HPD/FAD-CH groups is similar to the intended uptake in the HD groups at risk. The actual uptake may be much lower given the HD experience, ${ }^{36}$ which is illustrated by the finding that only a minority wishes testing immediately upon availability. As in the HD studies, participants at risk for HPD/FAD-CH emphasised the need for extensive pretest counselling and psychological assessment. Again, the group that requires predictive testing should also be informed about alternative ways of dealing with the issues that led to uptake of the test. Psychotherapy or behavioural therapy might help people to cope better with their anxieties. Couples could be supported in exploring other ways of dealing with their wish to have children. Predictive testing programmes seem to be subject to the "technological imperative". Therefore, the counsellor should approach applicants with full respect for their opinions but must also play the role of the devil's advocate when trying to discuss the pros and cons of testing and consideration of alternative coping strategies. However, this requires a closer collaboration of clinical genetics services and instititions of mental health.

Predictive testing for presenile dementia, such as Alzheimer's disease, should be undertaken only in the context of research protocols, using careful neurological and psychological assessments. ${ }^{24}$ Testing should not run unnoticed in a widespread clinical application without proper previous evaluation of such a service. However, predictive testing is generally considered, by both professionals and potential users, as a clinical service and not as a research protocol, with the consequence of a lack of follow up data, which hampers a thorough medical-ethical evaluation. Obviously, the relevance of mandatory research assessments for the evaluation of predictive testing should be clarified. Consequently, the contribution to the improvement of the clinical service must be convincing. If these requirements are met, people should be encouraged to participate in research assessments, and to adhere to the provisions of a research protocol. This may be an appropriate expectation by those offering presymptomatic testing for HPD or FAD-CH and HPD.

One special issue that was not addressed by the Alzheimer's study group, ${ }^{24}$ but which needs attention, concerns those at $25 \%$ risk, who are asymptomatic grandchildren of affected subjects. Identification of a person at $25 \%$ risk as a gene carrier identifies the unaffected, intervening, parent as a carrier of the disease 
mutation. Moreover, sibs would see their risks increase to $50 \%$. After the identification of the HD gene, recommendations for presymptomatic testing included a statement regarding those at $25 \%$ risk. These recommendations stated that extreme care should be exercised when testing a person at risk would inadvertently provide information about another person who has not requested the test. In such cases, every effort should be made by the counsellors and the subjects concerned to provide a satisfactory resolution of this conflict. ${ }^{20}$ The majority of representatives from lay organisations favoured the opinion that if no consensus could be reached, the right of the person at $25 \%$ risk should have priority over the right of the parent not to know. An important argument is that planning a family may be the main reason for young adults to take the test, whereas their unaffected parents see their chances of ever developing HD dramatically decrease after the age of 50 . Those at risk for presenile dementia are approaching the mean age of onset after 50 years of age, at a time when their children may start a family (threequarters of the grandchildren in the study group are older than 18 years). Thus, we expect more conflict of interests compared with $\mathrm{HD}$ and, in line with the HD guidelines, every effort must be made to solve such controversies both at an individual and a family level. The serious dilemma for the counsellor is whose rights and interests should prevail. Should the counsellor give priority to the applicant's right to know or should he deny testing in order to protect an invasion of the relatives' right not to know? Exclusion testing in a person at $25 \%$ risk may be a solution, that is, excluding whether or not one has received a chromosome from the affected grandparent. Such an outcome does not change the risk of the parent at $50 \%$ risk. However, the initial conflict arises again if the applicant's risk has increased to $50 \%$ and he/she wishes full certainty. Obviously, an unequivocal guideline is not compatible with the individual interests of all parties involved. The counsellor's responsibility is to safeguard that all advantages and disadvantages are discussed and weighed, with the inclusion of the impact of testing for relatives. Eventually, the test candidate should decide and have the responsibility for his decisions. It is obvious that inherited late onset disorders should be considered as a problem that may have affected the whole family for more than two generations. The family is therefore a relevant clinical frame of reference for the genetic counsellor and other health care professionals. ${ }^{183738}$

PRENATAL TESTING

When using the Dutch HD testing programme, one of the main aims was to obtain information useful for family planning. ${ }^{26}$ Family planning was found to be less important in the present survey of people at risk for HPD/FAD-CH. The majority were against the availability of prenatal diagnosis as a clinical service. Little more than half of those who supported such provision would use it personally and even in this group half of the respondents rejected pregnancy termination if an increased risk in the fetus was found. The eventual demand for HD prenatal testing was lower than was expected from pretest attitudes, but was constant over time (unpublished data presented at the 16th International Meeting of the World Federation of Neurology Research Group on Huntington's Disease, 1995). The expected use of prenatal diagnosis in HPD/FAD-CH might be even lower. This expected uptake might reflect feelings in the latter group that onset of the disease is generally later. ${ }^{939}$ These attitudes reflect the painful and thoughtful handling of options by those at risk and make clear the need for human compassion for people who have experienced the tragedy of the disease in their families. Hence, the individual request for prenatal diagnosis ought to be appreciated. However, access to prenatal diagnosis for untreatable late onset disorders should be denied to couples who would not consider a selective pregnancy termination, in order to prevent the violation of the future child's right not to know. In the present study, 10 out of 19 couples would opt for prenatal testing but not for selective abortion. This requires prudent counselling of couples before conception, if possible. This may be a task for the general practitioner followed by referral to a clinical genetics department.

Preimplantation genetic diagnosis may become an alternative in the near future. Recently, it has been suggested that preimplantation genetic diagnosis could be used as a method to achieve prevention of untreatable, autosomal dominant late onset disorders in offspring without disclosure of parental genotype. ${ }^{40}$ The couple would be told only that their embryos were tested, and that only apparently disease free embryos were replaced. No information would be given which might provide a basis for inferring whether or not any embryos with the mutation were identified. Hence, parents would derive no direct or indirect information about their own genetic risk, while preimplantation diagnosis could reduce the fetal risk to zero. This option could be valuable for parents at risk who prefer not to know their genetic status. It remains to be seen, however, whether this is a realistic alternative. First, the burdens and risks of in vitro fertilisation should not be underestimated. Furthermore, a condition would be to separate those involved in the testing procedure and the counsellor, otherwise it may become impossible to protect the parent's right not to know adequately.

\section{GENETICS AND DISCRIMINATION}

Both employers and the health, life, pension, or disability insurance companies may discriminate against people known to have an increased risk for cancer or neurodegenerative diseases. ${ }^{41}$ The Dutch debate on the person's duty to reveal genetic information to insurance companies, and on exclusion from life insurance of those at risk for HD and myotonic dystrophy, leads us to emphasise the potential harm to carriers of genes for untreatable genetic 
disorders with delayed onset. Our clinical experience has taught us that most people at risk for a variety of inherited late onset disorders are not aware of the risk of insurance and employment discrimination or tend to underestimate these issues. Some people have requested predictive testing in order to get access to life insurance. This experience underlines the need for further discussion regarding the use of genetic information by insurance companies and employers. We advocate that participants in genetic studies must be extensively informed of the potential hazards, which may lead to withdrawal from the protocol, or to delay testing until arrangements have been made. At the time of our study, much media attention was paid to discrimination based on genetic risks, which might explain why $20 \%$ of the participants held the opinion that test results should not be added to the medical records. Local legislation should protect people with a genetic susceptibility so that those at risk feel free to use the options of genetic testing, and scientists can proceed with research. ${ }^{41}$ Although legal, ethical, biomedical, and psychosocial issues must be extensively addressed in pre- and post-test counselling sessions, we are aware that the informed consent remains unsatisfactory and has many limitations with regard to these issues.

\section{GENETIC RESEARCH AND HEALTH CARE}

The increasing number of diseases that can be predicted by genetic testing (with far reaching consequences) raises the question of how genetics services and other medical disciplines can meet the need for careful pre- and post-test counselling and additional support. Although the need is acknowledged and emphasised in every study, the planning and resources required are rarely considered in most countries. This leaves the human aspect of genetics, such as psychological support and evaluation studies, dependent upon external, temporary financial support. Such lack of continuity in patient care and research and dissemination of clinical research findings may greatly endanger the quality of genetic medicine in the future.

Follow up care must provide proper and consistent information and support about the effects of test results on partner relationships and families. General practitioners must be properly informed about the impact of being at high risk on psychological well being. Health care providers must consider the complex psychological, ethical, and social issues in the application of presymptomatic testing. They should be aware of their own feelings of helplessness, ${ }^{42-44}$ and be careful not to consider the test as the only option. They must be educated on these issues in order to establish adequate support provisions.

\section{Conclusions}

The major limitation of this study was the relatively small number of participants. Another bias may be caused by the number of sibs in the study as four different families were involved. Therefore, the results must be considered with caution. The group studied may not be representative of the entire population at risk for presenile dementia. Moreover, the results, with the inclusion of the intention to have predictive testing when available, may have been biased by the extensive psychological attention of the researchers that the participants received. An important limitation is that the data were obtained by means of self-report. The disadvantages of self-report data are well known and include possible social desirability bias. Therefore, qualitative studies using observation and interview techniques and case studies conducted by people who are able to observe people at risk and their families objectively can improve the understanding of the observations which will consequently increase the clinical significance. The authors are very grateful to the people at risk and their
partners who have participated in this study. They are also grateful to Dr G C Beverstock for editing the manuscrip

1 Huntington's Disease Collaborative Research Group. A novel gene containing a trinucleotide repeat that is expanded and unstable on Huntington's disease chromosomes. The Huntington's Disease Collaborative Research Group. Cell 1993;72:971-83.

2 Gispert S, Twells R, Orozco G, et al. Chromosomal assignment of the second locus for autosomal dominant cerebellar ataxia (SCA2) to chromosome 12q23-24.1. Nat Genet 1993;4:295-9.

3 Haan J, Hardy JA, Roos RA. Hereditary cerebral hemorrhage with amyloidosis-Dutch type: its importance for Alzheimer with amyloidosis-Dutch type: its importan
research. Trends Neurosci 1991;14:231-4.

4 Mullan M, Crawford F, Buchanan J. Technical feasibility of genetic testing for Alzheimer's disease. Alzheimer Dis of genetic testing for Alzheim
Assoc Disord 1994;8:102-15.

5 Buxton J, Shelbourne P, Davies J, et al. Detection of an unstable fragment of DNA specific to individuals with myotonic dystrophy. Nature 1992;355:547-8.

6 Sherrington R, Rogaev EI, Liang Y, et al. Cloning of gene bearing missense mutations in early-onset familia Alzheimer's disease. Nature 1995;375:754-60

7 Hoogeveen AT, Willemsen R, Meyer N, et al. Characterization and localization of the Huntington disease gene product. Hum Mol Genet 1993;2:2069-73.

8 Hendriks L, van Duijn CM, Cras P, et al. Presenile dementia and cerebral haemorrhage linked to a mutation at codon 692 of the beta-amyloid precursor protein gene. Nat Genet 1992;1:218-21.

9 Heston LL, Mastri AR. Age at onset of Pick's and Alzheimer's dementia: implications for diagnosis and research. $\mathcal{f}$ Gerontol 1982;37:422-4.

10 Gustafson L. Frontal lobe degeneration of non-Alzheimer type. II. Clinical picture and differential diagnosis. Arch Gerontol Geriatr 1987;6:209-23.

11 Neary D, Snowden JS, Northen B, Goulding P. Dementia of frontal lobe type. $\mathcal{f}$ Neurol Neurosurg Psychiatry 1988 51:353-61.

12 Mendez MF, Selwood A, Mastri AR, Frey W. Pick's disease versus Alzheimer's disease: a comparison of clinical charversus Alzheimer's disease: a compariso
acteristics. Neurology 1993;43:289-92.

13 Harper PS. Huntington disease and the abuse of genetics. Am ₹ Hum Genet 1992;50:460-4.

14 Markel DS, Young AB, Penney JB. At risk person's attitude toward presymptomatic testing in Huntington disease. $A m$ f Med Genet 1987;26:295-305.

15 Meissen GJ, Berchek RL. Intended use of predictive testing by those at risk for Huntington disease. Am $\mathcal{F}$ Med Genet 1987;26:283-93.

16 Kessler S, Field T, Worth L, Mosbarger H. Attitudes of persons at risk for Huntington disease toward predictive testing. Am 7 Med Genet 1987;26:259-70.

17 Terrenoire G. Huntington's disease and the ethics of genetic prediction. F Med Ethics 1992;18:79-85.

18 Huggins M, Bloch M, Kanani S, et al. Ethical and legal dilemmas arising during predictive testing for adult-onset disease: the experience of Huntington disease. Am $\mathfrak{f} \mathrm{Hum}$ Genet 1990;47:4-12.

19 Hayden MR. Predictive testing for Huntington disease: are we ready for widespread community implementation? $\mathrm{Am}$ we ready for widespread comm

20 International Huntington Association and the World Fed eration of Neurology Research Group on Huntington's ration of Neurology Research Group on Huntington's thorea. Guidelines for the molecular genetics predictive

21 Quaid KA. Presymptomatic testing for Huntington's disease: the U.S. experience. Am 7 Med Genet 1992;51:1063.

22 Steenstraten IMvd, Tibben A, Roos RA, van de Kamp JJ Niermeijer MF. Predictive testing for Huntington disease: nonparticipants compared with participants in the Dutch program. Am $\mathcal{F}$ Hum Genet 1994;55:618-25. 
23 Lannfelt L, Axelman K, Lilius L, Basun H. Genetic counselling in a Swedish Alzheimer family with amyloid pre-

4ennox A, Karlinsky H, Meschino W, Buchanan JA, Percy Lennox A, Karlinsky $\mathrm{H}$, Meschino W, Buchanan JA, Percy
ME, Berg JM. Molecular genetic predictive testing for ME, Berg JM. Molecular genetic predictive testing for Alzheimer's disease: deliberations and preliminary re-
commendations. Alzheimer Dis Assoc Disord 1994;8:12647.

25 Karlinsky H, Sadovnick AD, Burgess MM, Langlois S, Hayden MR, Berg JM. Issues in molecular genetic testing of individuals with suspected early-onset familial Alzheimer's disease. Alzheimer Dis Assoc Disord 1994;8:11625.

26 Tibben A, Frets PG, van de Kamp JJ, et al. Presymptomatic DNA-testing for Huntington disease: pretest attitudes and expectations of applicants and their partners in the Dutch program. Am ₹ Med Genet 1993;48:10-16.

27 Heutink P, van Swieten JC, Stevens M, et al. The gene for hereditary Pick's disease maps to chromosome 17q21q22. Ann Neurol (in press).

28 Stevens $M$, van Duijn CM, Heutink P, et al. Hereditary Pick's disease. A comparison of clinical symptoms, radiological disease. A comparison of clinical symptoms, radiological
features and neuropathological changes between three features and neuropath

29 Gardner MJ, Altman DG. Statistics with confidence. Belfast: The Universities Press, 1989.

30 Mac Kay CR. Discussion points to consider in research related to the human genome. Hum Gene Ther 1993;4: 477-95.

31 Wiggins $S$, Whyte $\mathrm{P}$, Huggins $\mathrm{M}$, et al. The psychological consequences of predictive testing for Huntington's disease. Canadian Collaborative Study of Predictive Testing. $N$ Engl $\mathcal{H}$ Med 1992;327:1401-5.

32 Tibben A, Bannink EC, Timman RT, Duivenvoorden HJ. 3-year follow-up after presymptomatic testing for Huntington disease in tested individuals and partners. Health Psychol (in press).

33 Bloch M, Fahy M, Fox S, Hayden MR. Predictive testing for Huntington disease. II Demographic characteristics, life-style patterns, attitudes, and psychosocial assessments of the first fifty-one test candidates. Am 7 Med Genet 1989 ; 32:217-24.

34 Meissen GJ, Mastromauro CA, Kiely DK, McNamara DS, Myers RH. Understanding the decision to take the predictive test for Huntington disease. Am $\mathcal{F}$ Med Genet 1991; 39:404-10.

35 Feinberg J. The child's right to an open future. In: Aiken $\mathrm{W}, \mathrm{LaF}$ llette $\mathrm{H}$, eds. Whose child? Childrens' rights, parental authority, and state power. Totowa, New Jersey: Littlefield, Adams \& Co, 1980:124-53.

36 Quaid KA, Brandt J, Faden RR, Folstein SE. Knowledge, attitude, and the decision to be tested for Huntington's disease. Clin Genet 1989;36:431-8.

37 Kessler S. Forgotten person in the Huntingtor disease family. Am $\mathcal{F}$ Med Genet 1993;48:145-50.

38 Tibben A, Duivenvoorden HJ, Niermeijer MF, Vegter-vd Vlis M, Roos RAC, Verhage F. Psychological effects of presymptomatic DNA testing for Huntington's disease in the Dutch program. Psychosom Med 1994;56:526-32.

39 Roos RAC, Vegter-vd Vlis M, Hermans J, et al. Age at onse in Huntington's disease: effect of line of inheritance and patient's sex. F Med Genet 1991;28:515-19.

40 Schulman JD, Black SH, Handyside A, Nance WA. Preimplantation genetic testing for Huntington disease and certain other dominantly inherited disorders. Clin Genet 1996;49:57-8.

41 Culliton BJ. Genes and discrimination. Nat Med 1995;1: 385.

42 Martindale B. Huntington's chorea. Some psychodynamics seen in those at risk and in the responses of helping seen in those at risk and in the responses

43 Thies U, Bockel B, Bochdalofsky V. Attitudes of neurologists, psychiatrists, and psychotherapists towards predictive testing for Huntington's disease in Germany. $f$ Med Genet 1993;30:1023-7.

44 Thomassen R, Tibben A, Niermeijer MF, van der Does E van de Kamp JJ, Verhage F. Attitudes of Dutch genera practitioners towards presymptomatic DNA-testing for Huntington disease. Clin Genet 1993;43:63-8. 